This item was submitted to Loughborough's Research Repository by the author.

Items in Figshare are protected by copyright, with all rights reserved, unless otherwise indicated.

\title{
Don't try harder: using customer inoculation to build resistance against service failures
}

PLEASE CITE THE PUBLISHED VERSION

https://doi.org/10.1007/s11747-014-0398-1

\section{PUBLISHER}

(C) Academy of Marketing Science. Published by Springer

\section{VERSION}

AM (Accepted Manuscript)

\section{PUBLISHER STATEMENT}

This work is made available according to the conditions of the Creative Commons Attribution-NonCommercialNoDerivatives 4.0 International (CC BY-NC-ND 4.0) licence. Full details of this licence are available at: https://creativecommons.org/licenses/by-nc-nd/4.0/

\section{LICENCE}

CC BY-NC-ND 4.0

\section{REPOSITORY RECORD}

Mikolon, Sven, Benjamin Quaiser, and Jan Wieseke. 2014. “Don’t Try Harder: Using Customer Inoculation to Build Resistance Against Service Failures". Loughborough University. https://hdl.handle.net/2134/33443. 


\title{
Don't try harder: using customer inoculation to build resistance against service failures
}

\author{
Sven Mikolon, Benjamin Quaiser, and Jan Wieseke
}

Abstract

Capitalizing on a large-scale field experimental dataset involving 1,254 airline customers, this study introduces customer inoculation as a new, proactive strategy for mitigating the negative consequences that service failures have on customer satisfaction. Results confirm that customer inoculation eases the decrease in satisfaction when customers experience a service failure. Additional analyses indicate that customer inoculation does not harm customer satisfaction if no service failure occurs. This finding sets inoculation apart from expectation management and underscores the potential inoculation has for marketing practice. Furthermore, contrary to traditional recovery strategies for addressing service failures, customer inoculation operates in advance of a service failure and thereby circumvents potential drawbacks of traditional strategies. In sum, customer inoculation represents a novel strategy for addressing service failures with respect to existing marketing literature and expands the scope of action. 
Customer satisfaction (CS) is a key concept for marketers and a cornerstone in marketing theory (e.g., Fornell et al. 2010; Gupta and Zeithaml 2006; Zeithaml et al. 2006). Indeed, improving customer satisfaction is worthwhile in terms of multiple customer outcomes. For instance, satisfaction has a positive impact on customers' willingness to pay a price premium, on repurchases and customer retention, on customers' positive word of mouth, and on overall firm performance (e.g., Anderson and Mansi 2009; Anderson 1996; Fornell et al. 2006; Luo and Homburg 2007; Morgan et al. 2006; Seiders et al. 2005).

However, particularly in a service context, maintaining customer satisfaction is a bumpy ride that encounters at least two important obstacles. First, since variation in service performance is hard to avoid, service failures are very common (Lovelock and Gummesson 2004; Zeithaml et al. 1985). Second, external factors like customers or other service providers are closely tied to the service delivery process, making service failures less manageable for the focal company (Lovelock and Gummesson 1983; Rust and Chung 2006).

With respect to this dilemma, marketing theory has proposed two conventional strategies for circumventing the negative consequences of service failures: avoidance of failures by maintaining consistent performance levels and, in case avoidance fails, subsequent recovery of service failures. Both strategies succeed in terms of customer satisfaction. A stronger focus on maintaining a high performance level can help to retain and satisfy customers (e.g., Zeithaml, Berry, and Parasuraman 1996), and service (failure) recovery has positive effects on satisfaction and loyalty (Evanschitzky and Wunderlich 2006; Fang, Luo, and Jiang 2013; Smith, Bolton, and Wagner 1999; Spreng, Harrell, and Mackoy 1995).

However, both strategies have notable drawbacks. Failure avoidance is contingent on external factors, often leaving marketing executives with their hands tied (Lovelock and Gummesson 2004; Parasuraman, Zeithaml, and Berry 1985). For example, although customer integration best serves customers' idiosyncratic needs, these efforts do not always increase customer satisfaction (Chan, Yim, and Lam 2010). Moreover, improvements in service performance can be accompanied by lower profitability (Anderson et al. 1997; Rust et al. 2012), diminishing returns (Augustin and Singh 2005), and increases in costs because customers will not accept decreased performance (Haisley and Loewenstein 2011; Rust et al. 2000).

The success of the second strategy, service recovery, also depends largely on external factors. Influential factors include how strongly customers consider the recovery to be an obligation of the company (Wan et al. 2011), how well the divergent interests of the customer and firm employees are aligned (Michel, Bowen, and Johnston 2009), and the degree to which customers perceive themselves as responsible for the failure (Pham et al. 2010). Furthermore, the effectiveness of service recovery is influenced by failure quantity (Maxham et al. 2002) as well as the recovery's adequacy (Keaveney 1995). Finally, service recovery is usually costly, and opportunistic customer behavior can pose a challenge for large, transaction focused firms, which also makes service recovery less efficient (Wirtz 2011;Wirtz andMcColl-Kennedy 2010). Summing up, both strategies have limited effectiveness owing to external factors and constrained efficiency owing to higher costs.

To address these shortcomings of traditional approaches, we introduce customer inoculation as a promising strategy for bolstering customer satisfaction against service failures in advance of their potential occurrence. Figure 1 shows how customer inoculation adds to existing marketing strategies. Inoculation theory posits that when previously held attitudes or beliefs are intentionally challenged by minor counterarguments, people will develop mental defense strategies that help them maintain these attitudes or beliefs even when stronger challenges occur in the future (McGuire 1961; Papageorgis and McGuire 1961). Guided by social psychological findings that have demonstrated the ability of inoculation to strengthen attitudes against change (e.g., Banas and Rains 2010), we propose that customer inoculation effectively shields customer satisfaction against service failures. Importantly, inoculation works as a strategy in advance of possible attacks on customer satisfaction. This is important as previous research in marketing has largely neglected preventive strategies in favor of reactive recovery strategies.

Specifically, we address the following research questions: (1) How effectively does customer inoculation bolster customer satisfaction against actual service failures? (2) How should inoculation messages for customers be formulated? (3) How great an effect does customer inoculation exert on customer satisfaction in a flawless service process? This third question is particularly important for marketing managers, as it rules out potential dysfunctional effects of customer inoculation that could be harmful for organizational performance. As customers are inoculated in advance of a possible service failure, and because inoculation messages typically contain a moderate degree of negative information about the focal firm, inoculation of customers could be a risky strategy in competitive markets, with the possible end result being a lowering of the likelihood of purchases. Therefore, this research question raises the issue of the practicability of customer inoculation for managerial practice.

To answer these research questions, we focused on a frequently occurring service failure that is not totally under management's control and conducted a field experiment with 1,254 customers of a large European airline. We tested two different forms of inoculation in comparison to a control group and found that results supported our hypotheses regarding customer inoculation's ability to mitigate the decrease of customer satisfaction in cases of service failures. Furthermore, we conducted additional analyses that revealed customer inoculation has no effect 
on satisfaction in the absence of service failures. Our results also imply that customer inoculation effectively bolsters customer satisfaction against service failures without altering customer expectations regarding service performance. Therefore, customer inoculation offers a new strategy for shielding customer satisfaction when service failures are inevitable.

This study makes several important contributions to marketing literature. First, this study expands literature on service research by introducing customer inoculation as a proactive strategy to bolster customer satisfaction in advance of a service failure. By contrast, previous research has focused largely on reactive strategies, such as the recovery after a service failure (e.g., Smith, Bolton, and Wagner 1999). In light of the ability of inoculation to strengthen existing beliefs against change (McGuire 1961; Papageorgis and McGuire 1961) and the shortcomings of reactive strategies, we make a first attempt to examine the potential of customer inoculation to safeguard satisfaction. As a new proactive strategy, customer inoculation could complement present strategies for mitigating negative consequences of service failures on customer satisfaction.

Furthermore, this study adds to more general service research that has explored the potential of altering customer expectations in a way to ultimately increase customer satisfaction (Diehl and Poynor 2010; Kopalle and Lehmann 2001; Boulding et al. 1993; Parasuraman, Zeithaml, and Berry 1985). While this stream of research has yet not explicitly considered expectation management as a possible strategy to mitigate negative consequences of service failures on satisfaction, studies have demonstrated that lowering service expectations can lead to higher customer satisfaction (e.g., Diehl and Poynor 2010; Kopalle and Lehmann 2001). Thus expectation management could potentially preserve satisfaction levels in the event of service failures. However, a possible downside of expectation management is that strategically lowering customers' expectations of a service provider could actually result in preventing customers from using the focal service provider in competitive markets (Boulding et al. 1993). Our additional analyses reveal that customer inoculation can overcome this pitfall, as it has no effect on satisfaction for customers who became inoculated but did not experience a service failure. This finding underpins our theoretical proposition that customer inoculation stabilizes customer satisfaction against slippage rather than changing satisfaction by altering expectations. Our study therefore opens up several interesting lines of inquiry regarding the use of inoculation beyond mere mitigation of service failures.

Finally, we are able to capitalize on field experimental data from 1,254 airline customers, enabling us to contribute to the more general literature on inoculation. Previous work in this domain has largely drawn on laboratory experiments that have only limited external validity, and our study responds to a call for field experiments that demonstrate direct applicability of inoculation in real-world settings (Kamins and Assael 1987; Wagner, Lutz, and Weitz 2009). In addition, our findings provide managers with important insights about customer inoculation as a means of resolving the often unmanageable dilemma of maintaining customer satisfaction when the service process depends on external factors. In summary, the negative impact of service failures on customer satisfaction can be significantly attenuated by using customer inoculation as a preventive strategy, applied in advance of such likely occurrences.

Insert Figure 1 about here

\section{Inoculation theory}

Developed within the field of social psychology, inoculation theory is guided by the objective of making communication more persuasive and is used to explain how people build resistance against persuasion (McGuire 1961; Papageorgis and McGuire 1961). In particular, it is based on research on two-sided communication, which provides both positive and negative information about an issue (Crowley and Hoyer 1994; Eisend 2006; Lumsdaine and Janis 1953; Rucker, Petty, and Brinol 2008). The developers of inoculation theory worked from a biological analogy. That is, just as people are better protected against infectious diseases when they have been immunized by a weakened form of an infectious virus, people presented with a weakened form of negative information will be less willing to adopt counterarguments and to change their existing attitudes when confronted with real negative information (Papageorgis and McGuire 1961). Inoculation is said to work because the weakened form of counterarguments elicits threat and the supportive arguments can be used as scripts to strengthen existing attitudes against subsequent influence (McGuire 1964). The threat component of inoculation forewarns of an impending attack and thusmotivates resistance by making salient the potential vulnerability of one's current belief to change (Banas and Rains 2010). Since people often lack the motivation to develop supportive arguments on their own as this is a cognitively demanding endeavor (Papageorgis and McGuire 1961), they can use the supportive arguments to bolster their existing attitudes. Therefore, in line with the aim of making attitudes more persistent, original conceptualizations of inoculation theory suggest that rather than solely providing supportive arguments, a much more effective approach is to stimulate cognitive defense strategies by additionally confronting people with weakened forms of counterarguments (McGuire 1961; Papageorgis andMcGuire 1961). Consequently, successful inoculation messages should contain supporting 
arguments and a communication component that mildly threatens the personally held attitude. Although inoculation was originally applied to strongly held cultural truisms such as "we should brush our teeth after every meal if at all possible" (McGuire 1962, p. 241), further research has shown that the inoculation process works very similarly in a context with less pervasive attitudes, like opinions on controversial issues (e.g., Bither et al. 1971; Pryor and Steinfatt 1978; Szybillo and Heslin 1973).

Distinction between customer inoculation and expectation management

Within the disconfirmation of expectations paradigm typically applied in the service literature (Parasuraman, Zeithaml, and Berry 1985), customer expectations function as reference levels against which customers judge perceived service performance (e.g., Golder, Mitra, and Moorman 2012). If perceived service performance meets or exceeds expectations, the customer will be satisfied, whereas if the opposite is true, the customer will be less satisfied with the service (Homburg et al. 2009). Customer expectations form as a blend of what will and what should be delivered during the service on the basis of accumulated customer knowledge (Golder, Mitra, and Moorman 2012; Boulding et al. 1993). With regard to customer expectations management, several studies have demonstrated that lowering service expectations can lead to higher customer satisfaction because the gap between expected and experienced service increases, and positive disconfirmation is likely to result (e.g., Diehl and Poynor 2010; Kopalle and Lehmann 2001; Oliver 1980). Surprisingly, however, the effect is not always positive, as lower satisfaction levels can result (Boulding, Kalra, and Staelin 1999; see also Boulding et al. 1993 for the effect of different types of expectations on perceived service quality). Overall, customer expectations management is applied to alter customer expectations in a way that is ultimately aimed at increasing customer satisfaction. By contrast, inoculation theory is not targeted at changing attitudes. Rather, it is aimed at safeguarding customers’ existing attitudes, such as favorable satisfaction judgments against change (e.g., Bither et al. 1971). Inoculation messages typically contain a weak threat to the previously held belief, which should encourage people latently to develop defences against such possible attacks in the future but not change their attitudes or beliefs (Bechwati and Siegal 2005). Thus, if service failure occurs, inoculated customers are less susceptible to changing their preexisting positive attitude toward the service offering (cf. Kamins and Assael 1987). In this vein, inoculation theory should be viewed more as "a vehicle for instilling resistance against attitude slippage..., rather than as a tool to change attitudes” (Burgoon et al. 1995, p. 500).We return to this point in our additional analyses.

Using customer inoculation to bolster customer satisfaction against service failures

Previous marketing research has demonstrated the promising potential of inoculation for marketing applications, e.g., in the area of marketing communication (Ivanov et al. 2009; Kamins and Assael 1987; Kamins et al. 1987; Szybillo and Heslin 1973) or in generating cognitive responses in favor of a brand or product so as to lower the likelihood of product returns (Bechwati and Siegal 2005). We move beyond this work in that we explicitly apply inoculation to bolster customer satisfaction against service failures. We build on inoculation to shield customer satisfaction against service failures for two main reasons. First, inoculation seems to be particularly suited to be used in service contexts. This is because, as previous research on two-sided communication has found, discounting credence or experience attributes of an offering in an inoculation message is more effective than discounting search attributes in order to safeguard customers' existing attitudes against potential attacks in the future (Pechmann 1992). Since services are characterized by a relatively high share of credence and experience attributes (Sun, Keh, and Lee 2012), our application of inoculation in a service context is particularly consequential. Second, we expect customer inoculation to have an effect on customer satisfaction similar to that of inoculation on attitudes. According to previous research, inoculation reduces the likelihood of negative attitude change (e.g., Tannenbaum, Macaulay, and Norris 1966), because inoculation typically contains a mild threat to the previously held belief. Exposure to a mild threat in advance of a possible attack motivates customers to shore up existing attitudes by developing defensive cognitions (e.g., Bechwati and Siegal 2005). Existing applications of inoculation theory therefore prevent negative attitude change by strengthening cognitions. Yet, customer satisfaction is not purely cognitively driven (Oliver 1993), because consumption or service experiences can elicit emotions that supplement the cognitive dimension of satisfaction judgments (Westbrook and Oliver 1991). In line with this, Oliver (1997, p. 319) has stated that emotion "coexists alongside various cognitive judgments in producing satisfaction.” However, according to meta-analytic evidence, the role of emotion is less important than the role of cognition in the formation of customer satisfaction (Szymanski and Henard 2001).We thus expect that inoculation can successfully shield customer satisfaction with a service or with specific service aspects against service failures. Establishing managerial relevance of inoculation theory by extending previous applications in marketing. Although previous applications of inoculation in marketing contexts have yielded important insights, they have limitations that have so far prevented managers from applying inoculation to marketing practice. In the present investigation we also seek to address these limitations 
by extending previous work on inoculation in marketing. The present investigation is the first to analyze the effect of customer inoculation in no-attack situations. Since customer inoculation is applied in advance of potential service failures, consideration of possible negative effects for customers who experience no failure is of strong interest for managers and scholars. So far no study has applied inoculation in a realistic field experiment. Instead, without exception subjects of all studies have been students who participated in laboratory experiments. Although often used in marketing research, student samples have significant downsides with regard to external validity and generalization and are appropriate only if they are the subject group of interest (Burnett and Dunne 1986). Consequently, previous researchers have called for inoculation's application outside the campus (e.g., Szybillo and Heslin 1973). Our study is responsive to this call for research in that it demonstrates the benefits of customer inoculation in a realistic company environment.

\section{Hypotheses development}

To address our research questions, we derive three hypotheses. While the first hypothesis relates to the overall effectiveness of inoculation, the second addresses the incremental effectiveness of a refuting element in inoculation messages. The third hypothesis pertains to customers' service involvement as an important boundary condition for the effectiveness of customer inoculation. The present investigation focuses on a service failure that relates to a specific aspect of the service process: the airline customer's waiting time for baggage.

Accordingly, we examine the customer's overall satisfaction with waiting time at the baggage claim after flights with the focal airline rather than overall satisfaction with the airline. Figure 2 provides an overview of the proposed hypotheses and covariates for which we controlled in our empirical model.

Insert Figure 2 about here

\section{Effect of customer inoculation on customer satisfaction}

Inoculation theory holds that confronting people with weakened forms of counterarguments to an existing attitude along with arguments supporting the existing attitude stimulates cognitive activity that bolsters the existing attitude (Banas and Rains 2010). Inoculation is said to work because the weakened form of counterarguments elicits threat to the existing attitude and the supportive arguments can be used as scripts to strengthen the existing attitude against subsequent attacks (McGuire 1964). To illustrate this basic form of inoculation, we provide concrete examples from this study's application in parentheses. Inoculation proceeds from customers' overall satisfaction with the waiting time at the baggage claim ( $\mathrm{t}_{1}$ ), which customers have experienced after previous flights with the focal airline ("Overall, I am very satisfied with the waiting time at the baggage claim that I have experienced when using [name of the airline] in the past.”). Inoculation then poses a mild threat to customers' given satisfaction level ("Unfortunately, long waiting times at the baggage claim cannot be eliminated completely, particularly during peak travel times and at busy airports.”), and additionally contains promoting arguments, on which customers can draw in order to justify their given satisfaction level ("Of course [name of the airline] works closely with the airport to streamline the processes in order to minimize the waiting time.”). We suggest that in a customer-company context, customers who are inoculated prior to a possible service failure, i.e., customers who receive a message containing a mild threat to their current satisfaction level along with information promoting their current satisfaction level, are likely to remain at a relatively higher level of satisfaction once a service failure occurs. This is because the threat component of inoculation forewarns customers of an impending attack and thus motivates them to develop defensive cognitions. Since developing defensive cognitions such as supportive arguments is a cognitively demanding endeavor (Papageorgis and McGuire 1961), customers can use the information promoting their initial attitude from the inoculation message to justify their given level of satisfaction. Hence, after a service failure, customers are likely to be more satisfied with the service provider when they have received an inoculation message. Accordingly, we propose:

H1: Once a service failure has occurred, customers who were inoculated in advance of the failure will exhibit significantly higher customer satisfaction than customers without inoculation.

\section{Refuting elements in customer inoculation}

Recall that inoculation typically includes a threat component in the form of a weakened attack on an existing attitude, and supportive arguments on which individuals can draw in order to justify their given attitude. Refuting elements are typically built into such inoculations to increase their effectiveness (Papageorgis and McGuire 1961). These refutations contain arguments refuting the impending attack, and thereby they 
additionally assist the inoculation process by providing arguments or evidence that can be used to refute arguments presented in the attitudinal attack (Banas and Rains 2010).

Incremental effect of an external explanation for the service failure in customer inoculation

Translating such refuting elements of inoculation into a services marketing context, we include external explanations for the impending service failure (e.g., the baggage handling system is managed by the airport not by the airline) as refuting elements into a customer inoculation. We argue that external explanations are effective refutations because service failures bring about tendencies among customers to seek the source of the negative event (Bougie et al. 2003; Taylor 1994; Bitner 1990). In this vein, research found that where the customer places blame for the service failure-internally to the service provider, or externally to anything in the service provider's environment-can be expected to influence customer satisfaction with the service provider (e.g., Bitner 1990). More specifically, if customers believe that the service provider is to blame for the service failure once it actually occurs, they are less satisfied with the provider than when they believe that the occurrence of the service failure is not the provider's fault. Along these lines we suggest that a customer inoculation which additionally contains an element offering an external explanation for the impending threat is more effective in terms of building resistance than an inoculation without this additional element. Therefore, we formally propose:

H2: Once a service failure has occurred, customers who were inoculated with an inoculation message containing an additional external explanation for the service failure in advance of the failure will exhibit significantly higher customer satisfaction than customers who were inoculated with an inoculation message not including an additional external explanation for the service failure.

The moderating role of customer service involvement

In line with the work of Zaichkowsky (1985), we define customer service involvement as the level of personal relevance that a service has for a customer. We explore the role of involvement as moderating variable because there is widespread agreement among marketing scholars that involvement influences customers' information processing (e.g., Howard and Kerin 2006; Park and Hastak 1994; Celsi and Olson 1988). We propose that for customers who exhibit relatively high levels of service involvement, a given form of inoculation will be less effective in protecting customer satisfaction against service failures than for customers who exhibit relatively low levels of service involvement. Such a link draws from social psychological research on involvement and from inoculation theory. Involvement typically motivates people to seek out new knowledge about the object of importance. For instance, research in social psychology confirms that people for whom an attitude is highly important are better able to retrieve information about that object from memory (Holbrook et al. 2005), and that the retrieved information tends to be unusually accurate (Krosnick 1990). Furthermore, involvement has been found to instigate an elaborative rehearsal process of new incoming information, which subsequently results in more elaborated knowledge structures in people's long-term memory (Holbrook et al. 2005). Along those lines, it is likely that involvement impacts the effectiveness of inoculation as it likely changes the shock value of an inoculation message for an individual (McGuire 1961, p. 185). Recall that the basic tenet of inoculation messages is to provide weakened forms of dissonant information, which in turn should motivate people to consider new attitude bolstering arguments. While the weakened form of counterarguments elicits threat to the existing attitude, the supportive and/or refuting arguments provided in the inoculation message can be used as scripts to bolster the existing attitude against subsequent attacks (McGuire 1964). This effect is however contingent on the shock value of the dissonant information — in case the shock value is not sufficiently high inoculation fails to motivate people to consider attitude-bolstering arguments.

Since the shock value is to a large extent determined by the perceived novelty of the dissonant information (Crowley and Hoyer 1994), it follows that for low-involved customers, who have acquired less deep-structured and detailed knowledge about the service, the mild threat of the inoculation treatment poses a surprising attack against their existing attitude. As a result, they are particularly likely to consider satisfaction bolstering arguments. By contrast, the same inoculation treatment will have only limited shock value for highly involved individuals who know almost every detail of the service. It is likely that these customers are already aware of the negative information contained in a given inoculation message. As a result, they will not be sufficiently motivated to consider satisfaction-bolstering arguments. Even if high involvement led to enhanced thinking about the content of the inoculation message, the shock value is determined by the novelty of the dissonant information (Crowley and Hoyer 1994). Thus, enhanced thinking would only lead high-involved customers to uncover more easily that the inoculation does not contain any surprising discounting information for them. They might even perceive the inoculation message as merely belaboring the obvious. In a similar vein, Petty and Cacioppo (1979) found that involvement can reduce persuasion in case the arguments presented are obvious. A 
given form of customer inoculation, either including an external explanation for the service failure or not, should therefore be more effective in cases of low involved customers than in cases of highly involved customers. We thus propose:

H3: Service involvement negatively moderates the positive effect of customer inoculation on customer satisfaction once a service failure has occurred, such that for high involved customers inoculation is less effective in bolstering customer satisfaction against service failures than for low-involved customers.

\section{Methodology \\ Field experiment}

Testing our hypotheses requires at least two important boundary conditions to be met by the choice of service failure and experimental condition. First, the service failure must be relevant to the customer. Yet, as the occurrence of a service failure is uncertain, "systematic empirical research [is] difficult to conduct" (Smith et al. 1999, p. 356). Moreover, from a company’s perspective, informing customers of the possibility that a service failure might occur carries some risk, as customers' attention could turn to the inability of the company to avoid the failure. Nonetheless, an experiment that fits this condition would increase external validity as well as the likelihood of making an application in marketing practice. Second, to demonstrate the benefits of customer inoculation where external factors must be considered, a service failure that is not totally under a company's control would be most suitable. Consistent with these critical requirements, we conducted a field experiment in which customers experienced the entire service process of a regular airline flight and were unaware that they had participated in an experiment (Harrison and List 2004). In addition, the service failure involved was likely to be experienced by customers and was relevant to them. In collaboration with a large European airline, we inoculated customers with different messages prior to the service failure's occurrence. All inoculation messages appear in the Appendix. We focused on a frequently occurring service failure in this industry: a waiting time for checked baggage that customers perceived as too long. Furthermore, the service failure depends on a factor external to the service delivery process. Because extended waiting time results from delays in baggage transport from the aircraft to the airport terminal and/or baggage carousel, the airport, rather than the airline, is responsible for the failure.

\section{Participants}

The participants in our field experiment were customers who made a one-way or return flight to a specific summer destination. For this destination and travel season, the airline management assumed a higher occurrence of the service failure. Customers were randomly selected and through e-mail were invited by the airline to participate in an online customer satisfaction survey regarding their flight experience. In return for participating, customers could win different travel packages. The 2,600 customers who agreed to participate (a $26 \%$ response rate) received an e-mail seven days before their first flight. This e-mail included the pre-test satisfaction survey, followed by the inoculation message (which was not included for the control group). One day after their last flight they received the second e-mail, which included the post-test satisfaction measurement. A total of 1,353 customers (52 \%) took part in both surveys. Because careful reading of the inoculation messages was a prerequisite for evaluating the inoculation's effectiveness, we excluded 60 customers who received an inoculation treatment but wrongly answered two questions that checked understanding. Furthermore, we purged 13 customers from the dataset who experienced a complete loss of their checked baggage during the flights. Finally, in line with Ng and Houston (2009), we removed 26 outliers (1.9\%) from the dataset.

Overall test population This procedure resulted in a test population of 1,254 customers, of which 541 customers received an inoculation and 478 received an inoculation containing an external explanation for the service failure as additional refuting element. There were 235 customers in the control group who received no customer inoculation. Overall, 59 \% were male. The average age was similar to the airline's total customer population $(\mathrm{M}=49.13)$.

Test population with experienced service failure Given that our aim is to examine the potential of inoculation to immunize customers against service failures, the occurrence of a service failure is a necessary prerequisite for testing our hypotheses. A service failure can be defined as an incident that happens during the process of service delivery and causes a customer to subjectively perceive a loss. Losses can pertain to customers' economic resources, such as time or money, or to social resources, such as status or esteem (Smith, Bolton, and Wagner 1999). In line with this definition, we asked customers in the post-test survey whether they had subjectively perceived the waiting time for checked baggage as too long on a categorical scale, including the answers "No," coded with a "0,” and "Yes,” coded with a "1.” Overall, 433 customers of the overall test population indicated 
that their waiting time had been too long, so they had experienced the service failure. Prior to their flights and thus to their experience of the service failure, 182 of them had received a basic inoculation and 170 had received an inoculation containing an external explanation for the service failure as additional refuting element. Eighty one of these 433 customers who had experienced the service failure were in the control group and had received no inoculation. Overall, $63 \%$ were male. The average age was similar to the airline's total customer population $(\mathrm{M}=49.08)$.

\section{Measures}

We measured customers' satisfaction with the waiting time at the baggage claim on a seven-point scale ranging from 1 (totally disagree) to 7 (totally agree), using the following item: "Overall, how satisfied are you with the waiting time for checked baggage, when flying with [company name]?” We measured customers’ overall satisfaction with the company using three items adopted from Homburg, Koschate, and Hoyer (2005). A sample item is "All in all I am very satisfied with this airline." All items were measured on a seven-point scale (1=totally disagree, $7=$ =totally agree). Customer service involvement was measured with a short version of the well-established scale developed by Zaichkowsky (1985), including seven items (see also van Trijp, Hoyer, and Inman 1996). Example items are "I am very interested in air travels, airplanes, and airlines" and "Everything that is involved with flights is interesting to me.” All items were measured on a seven-point scale (1=totally disagree, $7=$ totally agree).

Covariates Customers often experience anger as a consequence of service failures (Laros and Steenkamp 2005; Nyer 2000; Richins 1997). Since anger is a strong negative emotional reaction it can decrease customer satisfaction with the service (e.g., Smith et al. 2002). We therefore deemed it important to control for customers' experienced level of anger in predicting their satisfaction in case the service failure had occurred. Thus, in case of service failure experience, we additionally asked customers to indicate the extent to which they experienced feelings of anger due to waiting times at the baggage claim on a seven-point semantic differential scale, ranging from 1 (not at all) to 7 (very much). Furthermore, since airline flights are frequently delayed and have been found to influence customers' overall service evaluations of airlines (Taylor 1994), we controlled for these delays in predicting customer satisfaction. The airline tracked whether a flight was delayed. We matched objective data on flight delays from the airline and customer responses using the respective flight number. We dummy-coded the occurrence of flight delays. We used " 1 ," when the respective flight was delayed, and used " 0 ” for non-delayed flights. We measured customers" age and gender (dummy-coded, with " 1 ”=female and "2"=male) with respective single-item measures in the questionnaire. Table 1 provides the psychometric properties and correlation coefficients of the focal constructs based on the overall sample of 1,254 customers.

\section{Results}

Relevance of the service failure

Prior to testing our hypotheses we examined the relevance of waiting time at the baggage claim for customers' satisfaction judgments. To this end, we tested whether customers' experience of the service failure had an impact on their satisfaction with the waiting time at the baggage claim ( $\mathrm{t}_{2}$ ). Testing this relationship is important, as inoculating customers against service failures that have no impact on customer satisfaction would be meaningless. For this purpose, we conducted an analysis of covariance (ANCOVA). CS with waiting time at the baggage claim ( $\mathrm{t}_{2}$ ) served as dependent variable and the experience of a service failure as a factor. We controlled for CS with waiting time at the baggage claim ( $\left.\mathrm{t}_{1}\right)$. Results show that CS $\left(\mathrm{t}_{1}\right)(\mathrm{F}(1,1251)=70.16, \mathrm{p}<.01)$ has a significant impact on CS (t2). Importantly, we found a significant effect of the service failure on CS (t2) (F (1, $1251)=160.15, \mathrm{p}<.01)$, such that customers who had experienced the service failure $(\mathrm{M}=3.90)$ showed significantly lower satisfaction levels than customers who had not experienced the service failure $(\mathrm{M}=5.14)$ after the covariate CS ( $\left.\mathrm{t}_{1}\right)$ was controlled for.

Hypotheses We tested our hypotheses using regression analyses. Following the group code approach (Aiken, Stein, and Bentler 1994), we introduced two dummy-coded variables to represent customers' group membership in one of the three experimental groups - the inoculation group (coded " 1 " for inoculation and " 0 " for the other two groups), the inoculation group with additional external explanation as refuting element (coded " 1 ” for inoculation with external explanation and " 0 ” for the other two groups), or the control group (coded " 1 ” for control group and "0” for the other two groups).

By using an assessment of satisfaction with waiting time at the baggage claim prior to the experimental intervention as covariate in our model, we controlled for individual differences on that measure when evaluating 
treatment effects (Russell et al. 1998). We further controlled for anger experienced by the customers as a consequence of the service failure (e.g., Smith et al. 2002). Finally, we controlled for whether the flight itself was delayed, for customers' age, and for gender. Table 2 presents the results of the regression analyses. For testing $\mathrm{H} 1$ and H2, we ran a main-effects model (Model 1) only. For testing H3, we additionally included the meancentered scores of customer service involvement (Aiken et al. 1991) and the respective interaction terms of involvement and the inoculation treatments into the model (Model 2). Hypothesis 1 predicts that customers who were inoculated in advance of the failure will exhibit significantly higher satisfaction than customers without inoculation. Results reveal that a basic customer inoculation has a significantly positive effect on CS ( $\mathrm{t}_{2}$ ) $(\mathrm{b}=.344, \mathrm{SE}=.176, \mathrm{p}<.05)$. Thus, customers who had received a basic inoculation treatment in advance of the service failure showed significantly higher satisfaction after the service failure $(M=3.80)$ than customers in the control group ( $M=3.45$; see Fig. 3). Hence, customer inoculation bolsters customer satisfaction against possible service failures, and $\mathrm{H} 1$ is supported. We propose in $\mathrm{H} 2$ that an inoculation including an external explanation for the service failure as additional refuting element is more effective in bolstering customer satisfaction against service failures than an inoculation not including this additional element. The difference in effect sizes of the inoculation treatments (inoculation $\mathrm{b}=.344, \mathrm{SE}=.176, \mathrm{p}<.05$; inoculation (ext. explanation) $\mathrm{b}=.644, \mathrm{SE}=.176, \mathrm{p}<.01$ ) provides an initial indication in support of this hypothesis. To fully test H2, we compared Model 1 (main-effects model) with a model in which we constrained the unstandardized regression coefficients of both inoculation treatments to be equal. We then compared the models using the Satorra-Bentler scaled likelihood-ratio test (Satorra and Bentler 2001). Results reveal a significant drop in model fit $\left(\Delta \chi_{2}=4.28, \mathrm{df}=1, \mathrm{p}<.05\right)$ when the regression coefficients of both inoculation treatments are constrained to be equal. Thus, the effect of inoculation including an additional external explanation for the service failure on customer satisfaction with the waiting time at the baggage claim ( $\left.\mathrm{t}_{2}\right)$ is significantly stronger $(\mathrm{M}=4.10)$ than the effect of inoculation not including such an external explanation ( $M=3.80$; see Fig. 3). In sum, these results support H2.

Insert Figure 3 about here

Finally, we found a significant negative moderation effect of customers' service involvement on the relationships between both customer inoculation treatments and CS with waiting time ( $\left.\mathrm{t}_{2}\right)$, supporting $\mathrm{H3}$ $(\mathrm{b}=-.348, \mathrm{SE}=.145, \mathrm{p}<.05 ; \mathrm{b}=-.295, \mathrm{SE}=.150, \mathrm{p}<.05)$. In order to facilitate interpretation of the interaction, we conducted a spotlight analysis (Goodman and Irmak 2013; Irwin and McClelland 2001; see Fig. 4).

Furthermore, we calculated simple slopes, which can in this case be interpreted as the difference of CS ( $\left.\mathrm{t}_{2}\right)$ between the respective inoculation group and control group for different levels of service involvement. We found that customer inoculation significantly increases CS ( $\left.\mathrm{t}_{2}\right)$ after customers had experienced the service failure when service involvement was low ( $b=.774, \mathrm{SE}=.319, \mathrm{p}<.05$ for -1 s.d.) and for an average level of service involvement ( $\mathrm{b}=.341, \mathrm{SE}=.134, \mathrm{p} \leq .05$ for $+/-0$ s.d.). However, for highly involved customers, customer inoculation did not exert a significant impact on CS ( $\mathrm{t} 2)$ after the occurence of a service failure $(\mathrm{b}=-.009$, $\mathrm{SE}=.109$, ns for +1 s.d.). Likewise we found that customer inoculation, including an additional external explanation for the service failure significantly increases CS (t2) after customers had experienced the service failure when service involvement was low $(\mathrm{b}=1.01, \mathrm{SE}=.343, \mathrm{p}<.01$ for -1 s.d.) and for an average level of service involvement ( $\mathrm{b}=.644, \mathrm{SE}=.184, \mathrm{p}<.01$ for $+/-0$ s.d.). However, for highly involved customers, customer inoculation including an additional external explanation for the service failure did not exert a significant impact on CS (t2) after the occurrence of a service failure ( $b=.277, \mathrm{SE}=.167$, ns for +1 s.d.).

Insert Figure 4 about here

Additional analyses

In addition to our main analysis, we path-analytically tested whether customer satisfaction with the waiting time at the baggage claim (t2) would mediate the relationship between service failure and overall CS ( $\mathrm{t}_{2}$ ) (Schneider et al. 2005). We controlled for involvement and overall CS ( $\left.\mathrm{t}_{1}\right)$. In order to test for the significance of the indirect effects, we conducted bootstrapping analyses (Schneider et al. 2005; MacKinnon et al. 2002). Bootstrapping analysis is similar to the Sobel test (Sobel 1982) but is robust against violations of normal distribution and gives reasonable control of Type I errors (Preacher and Hayes 2008; Schneider et al. 2005). We created 5,000 bootstrap samples and thus 5,000 estimates of the indirect effect. We found a significant negative indirect effect of service failure on overall satisfaction ( $\left.\mathrm{t}_{2}\right)$, mediated through CS with the waiting time at the baggage claim ( $\mathrm{t} 2)(\mathrm{b}=-.524, \mathrm{SE}=.050, \mathrm{p}<.01)$, with a 99\%c onfidence interval between -.649 to -.399. Notably, the direct effect of service failure on overall satisfaction lost significance when we added CS with the waiting time as mediator. Together with the significant indirect effect, this finding indicates that CS with the waiting time at the baggage claim ( $\mathrm{t} 2$ ) fully mediates the relationship between service failure and overall customer satisfcation ( $\left.\mathrm{t}_{2}\right)$. 
Customer inoculation and customer expectations The literature widely recognizes expectations as an integral part of a customer's evaluation process, leading to customer satisfaction (Fornell et al. 1996; Oliver 1993; Rust et al. 1999; Golder, Mitra, and Moorman 2012). Specifically, explicit service promises (as in advertising and corporate communication) affect customer expectations for desired and adequate service performance (Zeithaml, Berry, and Parasuraman 1993). With respect to its inherent threat, one might argue that customer inoculation would decrease customers' expectations by informing customers that a service failure can potentially occur. If this decrease were to prove true, using customer inoculation would be a risky undertaking for companies because lowering customer expectations is likely to put the focal firm in an inferior position compared to competitors. In line with the notion that customer expectations regarding service performance influence satisfaction with the experienced service, an assumed influence of inoculation on customers' expectations should subsequently affect customer satisfaction. Therefore, we additionally analyzed the influence of inoculation on customers who had not experienced the service failure after the treatment. We conducted an ANCOVA with CS with the waiting time at the baggage claim ( $\left.\mathrm{t}_{2}\right)$ as dependent variable and CS with the waiting time ( $\left.\mathrm{t}_{1}\right)$ as covariate. Whether a customer received a form of inoculation served as the factor. We performed the analysis using a subsample of only those customers who had not experienced the service failure. Results show that CS ( $\left.\mathrm{t}_{1}\right)(\mathrm{F}(1,818)=49.78, \mathrm{p}<.01)$ significantly influences CS ( $\left.\mathrm{t}_{2}\right)$. Likewise and most importantly, customer inoculation has no significant effect on satisfaction with the waiting time at the baggage claim of customers $\left(t_{2}\right)$ who did not experience the service failure $(F(1,818)=.272, p=.602)$. That is, satisfaction of customers who had received an inoculation message but did not experience the service failure ( $\mathrm{M}$ $=5.17$ ) is not significantly different from the satisfaction of customers who had not received an inoculation message and did not experience the service failure $(M=5.25)$. Thus, our data do not substantiate the assumption that customer inoculation affects customer expectations. Consequently, inoculating customers in advance of a possible service failure appears not to be harmful, even if not all recipients ultimately experience a flawed service process.

\section{General discussion}

Unfortunately, sustaining high service performance often remains an elusive goal for service companies. Customers' behaviors as well as occasional dependence on external service providers create difficulties for firms in controlling their service process. Indeed, service failures are a severe hazard for maintaining a consistently high level of customer satisfaction. Capitalizing on a large-scale field experimental dataset involving 1,254 airline customers, the current study introduces customer inoculation as a proactive strategy for dealing with service failures. Our findings demonstrate the usefulness of customer inoculation in mitigating the negative consequences of service failures on customer satisfaction. An additional analysis reveals that customer inoculation does not have a harmful effect on customers in the event that no service failure occurs. However, results also indicate that customer inoculation is ineffective for customers with a high level of service involvement.

\section{Theoretical implications}

In this study we are the first to apply inoculation theory to the field of service marketing. In so doing, we contribute to the service literature in a profound way. Specifically, we demonstrate that customer inoculation is viable as an alternative strategy for handling the inevitability of service failures and mitigating their negative consequences on customer satisfaction. In this domain scholars have hitherto largely focused on reactive service recovery strategies to deal with service failures (e.g.,Wan et al. 2011; Pham et al. 2010; Michel, Bowen, and Johnston 2009). In this study, we move beyond existing research by introducing customer inoculation as the first strategy to directly prepare customers in advance of a possible service failure. This contribution is particularly consequential because traditional reactive strategies have significant drawbacks which can seriously undermine their effectiveness (e.g., Wirtz 2011; Wirtz and McColl-Kennedy 2010). Moreover, our findings imply that customer expectations are not affected by inoculation messages, providing a further argument for customer inoculation as a distinctive new strategy in services marketing. In summary, we broaden marketing's scope of action to mitigate negative consequences of service failures. Yet, since we find that customer inoculation is not effective for customers with high levels of service involvement, future scholars may wish to investigate how inoculation can be best used in combination with traditional service recovery strategies in order to also bolster satisfaction of highly involved customers against service failures. Our findings should provide the foundation for further applications of customer inoculation in the field of marketing. For example, promising situations where customer inoculation could also help prevent customer dissatisfaction include negative price perceptions as well as having a limited number of points of sale for specific products or brands. Furthermore, our study makes two important contributions to more general research on inoculation in marketing. First, we extend 
previous work in that we explicitly investigate inoculation's potential for bolstering customer satisfaction. No study to date has used inoculation to support customer satisfaction against service failures. Previous work has predominantly focused on ways to design advertisements in order to make them more persuasive (e.g., Ivanov et al. 2009; Kamins and Assael 1987; Kamins et al. 1987). Second, the present investigation is the first to analyse the effect of customer inoculation in no-attack situations. Since inoculation always involves discounting attributes of the offered service or product, it was hitherto unclear if inoculation would be harmful in the event of no subsequent attack. Therefore, considering possible negative effects of inoculation on customers is a particularly novel contribution with respect to previous research. It is furthermore particularly important in the domain of services marketing since customer inoculation is applied in advance of potential service failures. Finally, our study also elaborates previous research on inoculation outside the field of (services) marketing. Most of the findings in this domain are based on lab studies, creating a need for verification in the field. Our field experimental approach allows us to verify findings from the lab that inoculation is effective in building psychological resistance against attitude change. Since we applied customer inoculation in a field experiment rather than in an artificial laboratory setting our study uniquely demonstrates the managerial benefits of customer inoculation in a realistic company environment.

\section{Managerial implications}

Particularly in service industries, performance levels are often unpredictable. External factors, including customers themselves as well as other companies in the service delivery process, are not totally controllable by the focal service company. Given these service characteristics, failures often inevitably occur, and engaging in the conventional strategy of post-failure service recovery incurs considerable costs. Customer inoculation addresses this dilemma by providing managers with an additional strategy to manage service failures and diminish their negative effect on customer satisfaction. This new strategy complements traditional strategies like service improvements and service recovery, and it enlarges the pool of tools available to managers when they face the inevitable challenge of service failures. Our findings demonstrate that managers can use customer inoculation to bolster customers' satisfaction against service failures. Importantly, results also show that customer inoculation is even more effective if the company can redirect customers to attribute the service failure to external sources, such as a value-chain partner. This is indicated by the finding that inoculation containing an external explanation for the service failure is more effective in building psychological resistance against service failures than inoculation without an additional external explanation. However, managers should use such refuting elements in inoculation messages with caution. External explanations are only a viable option for managers when there is indeed an external entity responsible for the service failure. Even if this is the case, blaming value chain partners can ultimately be a zero-sum game. Doing so might damage the business relationship with the partner, and the partner might respond with engaging in the same activity. Thus, when using external explanations in inoculation messages managers should be aware of their potential to backfire. Furthermore, customer inoculation is the only strategy managers can use in advance of possible service failures without facing the risk of losing customers in competitive markets. For instance, while previous research has demonstrated that lowering customer expectations regarding service performance can increase customer satisfaction with the service, this strategy is risky, as customers might switch to competitors who they expect to deliver higher service performance (Diehl and Poynor 2010; Kopalle and Lehmann 2001). Finally, our findings should dispel concerns that customer inoculation has a negative impact on customer satisfaction in the absence of a service failure. These results give customer inoculation further relevance for several market applications where service failures are mostly unpredictable. Overall, companies can employ customer inoculation effectively, as it is very easy to create, quick to implement, and cost effective to use. Nevertheless, managers should not exclusively rely on customer inoculation as a means of managing customer satisfaction, because the effectiveness of inoculation depends on customers' service involvement. For customers exhibiting particularly high levels of involvement, the content of the inoculation message should be designed in such a way that it would still provide a sufficient shock value—so as to motivate them to also consider satisfaction bolstering arguments. 


\section{References}

Aiken, L. S., Stein, J. A., Bentler, P. M., \& West, S. G. (1991). Multiple regression: Testing and interpreting interactions. Newbury Park: Sage Publications.

Aiken, L. S., Stein, J. A., \& Bentler, P. M. (1994). Structural equation analyses of clinical subpopulation differences and comparative treatment outcomes: characterizing the daily lives of drug addicts. Journal of Consulting and Clinical Psychology, 62(3), 488-99.

Anderson, E. W. (1996). Customer satisfaction and price tolerance. Marketing Letters, 7(3), 265-274.

Anderson, E.W., Fornell, C.,\& Rust, R. T. (1997). Customer satisfaction, productivity, and profitability: differences between goods and services. Marketing Science, 16(2), 129-145.

Anderson, E. W., \& Mansi, S. A. (2009). Does customer satisfaction matter to investors? findings from the bond market. Journal of Marketing Research, 46(5), 703-714.

Augustin, C., \& Singh, J. (2005). Curvilinear effects of consumer loyalty determinants in relational exchanges. Journal of Marketing Research, 42(1), 96-108.

Banas, J. A., \& Rains, S. A. (2010). A meta-analysis of research on inoculation theory. Communication Monographs, 77(3), 281311.

Bechwati, N. N.,\&Siegal,W. S. (2005). The impact of the prechoice process on product returns. Journal of Marketing Research, 42(3), 358-367.

Bither, S. W., Dolich, I. J., \& Nell, E. B. (1971). The application of attitude immunization techniques in marketing. Journal of Marketing Research, 18(1), 56-61.

Bitner,M. J. (1990). Evaluating service encounters: the effects of physical surroundings and employee responses. Journal of Marketing, 54(2), 69-82.

Bougie, J., Roger, G., Rik, P., \& Marcel, Z. (2003). Angry customers don’t come back, they get back: the experience and behavioural implications of anger and dissatisfaction in services. Journal of the Academy of Marketing Science, 31(4), 377-393.

Boulding, W., Kalra, A., Staelin, R., \& Zeithaml, V. A. (1993). A dynamic process model of service quality: from expectations to behavioral intentions. Journal of Marketing Research, 30(1), 7-27.

Boulding, W., Kalra, A., \& Staelin, R. (1999). The quality double whammy. Marketing Science, 18(4), 463484.

Burgoon, M., Pfau, M., \& Birk, T. S. (1995). An inoculation theory explanation for the effect of corporate issue/advocacy advertising campaigns. Communication Research, 22(4), 485- 505.

Burnett, J. J., \& Dunne, P. M. (1986). An appraisal of the use of student subjects in marketing research. Journal of Business Research, 14(1), 329-343.

Celsi, R. L., \& Olson, J. C. (1988). The role of involvement and in attention and comprehension processes. Journal of Consumer Research, 15(2), 210-224.

Chan, K. W., Yim, C. K., \& Lam, S. S. (2010). Is customer participation in value creation a double-edged sword? evidence from professional financial services across cultures. Journal of Marketing, 74(3), 48-64.

Crowley, A. E., \& Hoyer, W. D. (1994). An integrative framework for understanding two-sided persuasion. Journal of Consumer Research, 20(4), 561-574.

Diehl, K., \& Poynor, C. (2010). Great expectations?! assortment size, expectations, and satisfaction. Journal of Marketing Research, 47(2), 312-322. 
Eisend, M. (2006). Two-sided advertising: a meta-analysis. International Journal of Research in Marketing, 23(2), 187-198.

Evanschitzky, H., \& Wunderlich, M. (2006). An examination of moderator effects in the four-stage loyalty model. Journal of Service Research, 8(4), 330-345.

Fang, Z., Luo, X.,\& Jiang, M. (2013). Quantifying the dynamic effects of service recovery on customer satisfaction: evidence from Chinese mobile phone markets. Journal of Service Research, 16(3), 341- 355.

Fornell, C., Johnson, M. D., Anderson, E. W., Cha, J., \& Bryant, B. E. (1996). The American customer satisfaction index: nature, purpose, and findings. Journal of Marketing, 60(4), 7-18.

Fornell, C., Johnson,M. D., Anderson, E.W., Jaesung, C., Everitt Bryant, B., Sunil, M., Morgeson, F. V., III, \& Krishnan, M. S. (2006). Customer satisfaction and stock prices: high returns, low risk. Journal of Marketing, 70(1), 3-14.

Fornell, C., Johnson,M. D., Anderson, E.W., Cha, J., Bryant, B. E., Rust, R. T., \& Dekimpe, M. G. (2010). The effect of customer satisfaction on consumer spending growth. Journal of Marketing Research, 47(1), 28-35.

Golder, P. N., Mitra, D., \& Moorman, C. (2012). What is quality? An integrative framework of processes and states. Journal of Marketing, 76(4), 1-23.

Goodman, J. K.,\& Irmak, C. (2013). Having versus consuming: failure to estimate usage frequency makes consumers prefer multifeature products. Journal of Marketing Research, 49(1), 44-54.

Gupta, S., \& Zeithaml, V. A. (2006). Customer metrics and their impact on financial performance. Marketing Science, 25(6), 718-739.

Haisley, E.,\& Loewenstein,G. (2011). It's not what you get but when you get it: the effect of gift sequence on deposit balances and customer sentiment in a commercial bank. Journal of Marketing Research, 48(1), $103-115$.

Harrison, G. W., \& List, J. A. (2004). Field experiments. Journal of Economic Literature, 42(4), 1009-1055.

Holbrook,A. L., Berent,M. K., Krosnick, J.A., Visser, P. S.,\& Boninger, D. S. (2005). Attitude importance and the accumulation of attitude relevant knowledge in memory. Journal of Personality and Social Psychology, 88(5), 749-769.

Homburg, C., Koschate, N., \& Hoyer, W. D. (2005). Do satisfied customers really pay more? a study of the relationship between customer satisfaction and willingness to pay. Journal of Marketing, 69(2), 84-96.

Homburg, C., Koschate, N., Hoyer, W. D., Wieseke, J., \& Hoyer, W. D. (2009). Social identity and the serviceprofit chain. Journal of Marketing, 73(2), 38-54.

Howard, D. J., \& Kerin, R. A. (2006). Broadening the scope of reference price advertising research: a field study of consumer shopping involvement. Journal of Marketing, 70(4), 185-204.

Irwin, J. R., \& McClelland, G. H. (2001). Misleading heuristics and moderated multiple regression models. Journal of Marketing Research, 38(1), 100-109.

Ivanov, B., Michael, P., \& Parker, K. A. (2009). Can inoculation withstand multiple attacks? an examination of the effectiveness of the inoculation strategy compared to the supportive and restoration strategies.

Communication Research, 36(5), 655-676.

Kamins, M. A., \& Assael, H. (1987). Two-sided versus one-sided appeals: a cognitive perspective on argumentation, source derogation, and the effect of disconfirming trial on belief change. Journal of Marketing Research, 24(1), 29-39.

Kamins, M. A., Assael, H., \& Marks, L. J. (1987). Advertising puffery: the impact of using two-sided claims on product attitude and purchase intention. Journal of Advertising, 16(4), 6-15. 
Keaveney, S. M. (1995). Customer switching behavior in service industries: an exploratory study. Journal of Marketing, 59(2), 7182.

Kopalle, P. K., \& Lehmann, D. R. (2001). Strategic management of expectations: the role of disconfirmation sensitivity and perfectionism. Journal of Marketing Research, 38(3), 386-394.

Krosnick, J. A. (1990). American’s perceptions of presidential candidates: a test of the projection hypothesis. Journal of Social Issues, 46, 159-182.

Laros, F. J. M., \& Steenkamp, J.-B. E. M. (2005). Emotions in consumer behavior: a hierarchical approach. Journal of Business Research, 58(10), 1437-1445.

Lovelock, C. H., \& Gummesson, E. (1983). Classifying services to gain strategic marketing insights. Journal of Marketing, 47(3), 9-20.

Lovelock, C. H., \& Gummesson, E. (2004).Whither services marketing? in search of a new paradigm and fresh perspectives. Journal of Service Research, 7(1), 20-41.

Lumsdaine, A. A., \& Janis, I. L. (1953). Resistance to “counterpropaganda” produced by one-sided and twosided “propaganda” presentations. Public Opinion Quarterly, 17(3), 311-318.

Luo, X., \& Homburg, C. (2007). Neglected outcomes of customer satisfaction. Journal of Marketing, 71(2), 133-149.

MacKinnon, D. P., Lockwood, C. M., Hoffman, J. M., West, S. G., \& Sheets, V. (2002). A comparison of methods to test mediation and other intervening variable effects. Psychological Methods, 7, 83-104.

Maxham, I. I. I., James, G., \& Netemeyer, R. G. (2002). A longitudinal study of complaining customers' evaluations of multiple service failures and recovery efforts. Journal of Marketing, 66(4), 57-71.

McGuire, W. J. (1961). The effectiveness of supportive and refutational defenses in immunizing and restoring beliefs against persuasion. Sociometry, 24(2), 184-197.

McGuire, W. J. (1962). Persistence of the resistance to persuasion induced by various types of prior belief defenses. Journal of Abnormal and Social Psychology, 64(4), 241-248.

McGuire, W. J. (1964). Inducing resistance to persuasion: some contemporary approaches. In L. Berkowitz (Ed.), Advances in experimental social psychology vol. 1 (pp. 191-229). New York: Academic.

Michel, S., Bowen, D.,\& Johnston, R. (2009).Why service recovery fails - tensions among customer, employee, and process perspectives. Journal of Service Management, 20(3), 253-273.

Morgan, Neil A. and Rego Lopo L. (2006). The value of different customer satisfaction and loyalty metrics in predicting business performance. Marketing Science, 25(5).

Ng, S., \& Houston, M. J. (2009). Field dependency and brand cognitive structures. Journal of Marketing Research, 46(2), 279-292.

Nyer, P. U. (2000). An investigation into whether complaining can cause increased consumer investigation. Journal of Consumer Marketing, 17(1), 9-19.

Oliver, R. L. (1980). A cognitive model of the antecedents and consequences of satisfaction decisions. Journal of Marketing Research, 17(4), 460-469.

Oliver, R. L. (1993). Cognitive, affective, and attribute bases of the satisfaction response. Journal of Consumer Research, 20(3), 418-430.

Oliver, R. L. (1997). Satisfaction: a behavioral perspective on the consumer. New York: McGraw-Hill. 
Papageorgis, D., \& McGuire, W. J. (1961). The generability of immunity to persuasion produced by preexposure to weakened counterarguments. Journal of Abnormal and Social Psychology, 62(3), 475-481.

Parasuraman, A., Zeithaml, V. A., \& Berry, L. L. (1985). A conceptual model of service quality and its implications for future research. Journal of Marketing, 49(4), 41-50.

Park, J.-W., \& Hastak, M. (1994). Memory-based product judgments: effects of involvement at encoding and retrieval. Journal of Consumer Research, 21(4), 534-547.

Pechmann, C. (1992). Predicting when two-sided ads will be more effective than one-sided ads: the role of correlational and correspondent inferences. Journal of Marketing Research, 29(4), 441-453.

Petty, R. E., \& Cacioppo, J. T. (1979). Issue involvement can increase or decrease persuasion by enhancing message-relevant cognitive responses. Journal of Personality and Social Psychology, 37(10), 1915-1926.

Pham, M. T., Goukens, C., Lehmann, D. R., \& Stuart, J. A. (2010). Shaping customer satisfaction through selfawareness cues. Journal of Marketing Research, 47(5), 920-932.

Preacher, K. J., \& Hayes, A. F. (2008). Asymptotic and resampling strategies for assessing and comparing indirect effects in multiple mediator models. Behavior Research Methods, Instruments, \& Computers, 40(3), 879-891.

Pryor, B., \& Steinfatt, T. M. (1978). The effects of initial belief level on inoculation theory and its proposed mechanisms. Human Communication Research, 4(3), 217-230.

Richins, M. L. (1997). Measuring emotions in the consumption experience. Journal of Consumer Research, 24(2), 127-146.

Rucker, D. D., Petty, R. E., \& Brinol, P. (2008). What's in a frame anyway?: a meta-cognitive analysis of the impact of one versus two sided message framing on attitude certainty. Journal of Consumer Psychology, 18(2), 137-149.

Russell, D. W., Kahn, J. H., Spoth, R., \& Altmaier, E. M. (1998). Analyzing data from experimental studies: a latent variable structural equation modeling approach. Journal of Counseling Psychology, 45, 18-29.

Rust, R. T., \& Chung, T. S. (2006). Marketing models of service and relationships. Marketing Science, 25(6), 560-580.

Rust, R. T., Chung, T. S., Jeffrey Inman, J., Jia, J., \& Zahorik, A. (1999). What you don't know about customerperceived quality: the role of customer expectation distributions.Marketing Science, 18(1), 77-92.

Rust, R. T., Chung, T. S., \& Oliver, R. L. (2000). Should we delight the customer? Journal of the Academy of Marketing Science, 28(1), 86-94.

Rust, R. T., Chung, T. S., \& Huang, M.-H. (2012). Optimizing service productivity. Journal of Marketing, 76(2), 47-66.

Satorra, A., \& Bentler, P. M. (2001). A scaled difference chi-square test statistic formoment structure analysis. Psychometrika, 66(4), 507-514.

Schneider, B., Ehrhart,M.G.,Mayer, D. M., Saltz, J. L.,\& Niles-Jolly, K. (2005). Understanding organizationcustomer links in service settings. Academy of Management Journal, 48(6), 1017-32.

Seiders, K., Voss, G. B., Grewal, D., \& Godfrey, A. L. (2005). Do satisfied customers buy more? examining moderating influences in a retailing context. Journal of Marketing, 69(4), 26-43.

Smith, A. K., Bolton, R. N., \& Wagner, J. (1999). A model of customer satisfaction with service encounters involving failure and recovery. Journal of Marketing Research, 36(3), 356-372. 
Smith, A. K., Bolton, R. N., \& Wagner, J. (2002). The effects of customers' emotional responses to service failures on their recovery effort evaluations and satisfaction judgments. Journal of the Academy of Marketing Science, 30(1), 5-23.

Sobel, M. E. (1982). Asymptotic confidence intervals for indirect effects in structural equation models. In S. Leinhardt (Ed.), Sociological methodology (pp. 290-312). San Francisco: Jossey-Bass.

Spreng, R. A., Harrell, G. D., \& Mackoy, R. D. (1995). Service recovery: impact on satisfaction and intentions. Journal of Services Marketing, 9(1), 15-23.

Sun, J., Keh,H. T.,\&Lee,A.Y. (2012). The effect of attribute alignability on service evaluation: the moderating role of uncertainty. Journal of Consumer Research, 39(4), 831-847.

Szybillo, G. J., \& Heslin, R. (1973). Resistance to persuasion: inoculation theory in a marketing context. Journal of Marketing Research, 10(4), 396-403.

Szymanski, D. M., \& Henard, D. H. (2001). Customer satisfaction: a meta-analysis of the empirical evidence. Journal of the Academy of Marketing Science, 29(1), 16-35.

Tannenbaum, P. H., Macaulay, J. R., \& Norris, E. L. (1966). Principle of congruity and reduction of persuasion. Journal of Personality and Social Psychology, 3(2), 233-238.

Taylor, S. A. (1994). An assessment of the relationship between service quality and customer satisfaction in the formation of consumers’ purchase intentions. Journal of Retailing, 70(2), 163-178.

van Trijp, H. C., Hoyer, W. D., \& Inman, J. J. (1996). Why switch? product category-level explanations for true variety-seeking behavior. Journal of Marketing Research, 33(3), 281-292.

Wagner, T., Lutz, R. J., \& Weitz, B. A. (2009). Corporate hypocrisy: overcoming the threat of inconsistent corporate social responsibility perceptions. Journal of Marketing, 73(6), 77-91.

Wan, L. C., Hui,M. K., \&Wyer, R. S., Jr. (2011). The role of relationship norms in responses to service failures. Journal of Consumer Research, 38(2), 260-277.

Westbrook, R. A., \& Oliver, R. L. (1991). The dimensionality of consumption emotion patterns and consumer satisfaction. Journal of Consumer Research., 18(1), 84-91.

Wirtz, J. (2011). How to deal with customer shakedowns. Harvard Business Review, 89(4), 24.

Wirtz, J., \& McColl-Kennedy, J. R. (2010). Opportunistic customer claiming during service recovery. Journal of the Academy of Marketing Science, 38(5), 654-675.

Zaichkowsky, J. L. (1985). Measuring the involvement construct. Journal of Consumer Research, 12(3), 341352.

Zeithaml, V. A., Berry, L. L., Parasuraman, A., Parasuraman, A.,\& Berry, L. L. (1985). Problems and strategies in services marketing. Journal of Marketing, 49(2), 33-46.

Zeithaml, V. A., Berry, L. L., \& Parasuraman, A. (1993). The nature and determinants of customer expectations of service. Journal of the Academy of Marketing Science, 21(1), 1-12.

Zeithaml, V. A., Berry, L. L., \& Parasuraman, A. (1996). The behavioural consequences of service quality. Journal of Marketing, 60(2), 31-46.

Zeithaml, V. A., Berry, L. L., Parasuraman, A., Bolton, R. N., Deighton, J., Keiningham, T. L., Lemon, K. N., \& Petersen, J. A. (2006). Forward-looking focus. Can firms have adaptive foresights? Journal of Service Research, 9(2), 168-183. 


\section{Appendix \\ Inoculation treatments}

Inoculation Treatment Abridged Version of Inoculation Messages

Customer Inoculation “X’s commitment to service quality has earned X several awards.

Furthermore, airport services are constantly being improved to make your trip as convenient as possible.

Unfortunately, long waiting times at the baggage claim cannot be eliminated completely, particularly during peak travel times and at busy airports.

Of course, $\mathrm{X}$ works closely with the airport to streamline the processes in order to minimize the waiting time. In addition, $\mathrm{X}$ regularly checks the waiting time at every airport, in order to fix problems as soon as possible.

Customer Inoculation with Additional Ext. Explanation

"X's commitment to service quality has earned X several awards.

Furthermore, airport services are constantly being improved to make your trip as convenient as possible.

Unfortunately, long waiting times at the baggage claim cannot be eliminated completely, particularly during peak travel times and at busy airports. Often the airline is blamed for this inconvenience. However, the baggage handling system is managed by the airport.

Of course, $\mathrm{X}$ works closely with the airport to streamline the processes in order to minimize the waiting time. In addition, $\mathrm{X}$ regularly checks the waiting time at every airport, in order to fix problems as soon as possible. 
TABLE 1

Psychometric Properties and Scale Intercorrelations of Focal Constructs (Overall Sample)

\begin{tabular}{|c|c|c|c|c|c|c|c|c|c|c|c|}
\hline Variable & $\alpha$ & 1 & 2 & 3 & 4 & 5 & 6 & 7 & 8 & 9 & 10 \\
\hline 1. Customer Satisfaction With the Waiting Time $\left(\mathrm{t}_{1}\right)$ & $-{ }^{a}$ & & $.275^{* *}$ & $.557 * *$ & $.237 * *$ & $.214^{* *}$ & $-.106 *$ & $-.075 * *$ & -.051 & $-.069 *$ & $-.174 * *$ \\
\hline 2. Customer Satisfaction With the Waiting Time $\left(\mathrm{t}_{2}\right)$ & $-{ }^{a}$ & & & $.207 * *$ & $.507 * *$ & $.077 * *$ & $-.211 * *$ & $-.154 * *$ & -.038 & -.029 & $-.368 * *$ \\
\hline 3. Overall Customer Satisfaction $\left(\mathrm{t}_{1}\right)$ & .92 & & & & $.363 * *$ & $.316^{* *}$ & -.064 & $-.087 * *$ & $.060 *$ & $-.077 * *$ & $-.094 * *$ \\
\hline 4. Overall Customer Satisfaction $\left(\mathrm{t}_{2}\right)$ & .94 & & & & & $.154 * *$ & -.061 & $-.218 * *$ & .003 & -.039 & $-.152 * *$ \\
\hline 5. Customer Service Involvement & .88 & & & & & & -.001 & -.043 & $.132 * *$ & .030 & -.031 \\
\hline 6. Anger ${ }^{b}$ & $-{ }^{a}$ & & & & & & & .048 & -.050 & $.096 *$ &..$^{\mathrm{d}}$ \\
\hline 7. Flight Delay ${ }^{c}$ & - & & & & & & & & -.019 & .013 & $.173^{* *}$ \\
\hline 8. Age & $-{ }^{a}$ & & & & & & & & & $.159 * *$ & .000 \\
\hline 9. Gender $^{\mathrm{e}}$ & - & & & & & & & & & & $.062 *$ \\
\hline 10. Service Failure (Too Long Waiting Time) ${ }^{b}$ & - & & & & & & & & & & \\
\hline
\end{tabular}

Notes: ${ }^{* *} p \leq .01,{ }^{*} p \leq .05$; Correlations are based on the overall sample (1254 customers).

${ }^{\mathrm{a}}$ Constructs are measured by a single item.

${ }^{\mathrm{b}}$ Correlations for anger are based on a sample of 433 customers. (We only asked customers who had experienced the service failure (too long waiting time) to indicate their experienced level of anger due to the failure

"Variable is dummy-coded ("0" non-occurrence of the failure; “1” occurrence of the failure).

${ }^{\mathrm{d}}$ Since we only asked customers who had experienced the service failure (too long waiting time) to indicate their experienced level of anger due to the failure this correlation cannot be computed.

"Variable is dummy-coded (“1” female; “2” male). 
TABLE 2

Estimates and Regression Coefficients

Relationships

Effect of Customer Inoculation on Customer Satisfaction

Customer Inoculation $\rightarrow \mathrm{CS}\left(\mathrm{t}_{2}\right)$

Customer Inoculation (Ext. Explanation) $\rightarrow$ CS ( $\left.\mathrm{t}_{2}\right)$

Model 1
(Main-Effects-Model)

Model 2 (Full-Model)

Moderating Effect of Customer Service Involvement

Service Involvement x Customer Inoculation $\rightarrow$ CS ( $\left.\mathrm{t}_{2}\right)$

$.344(.176)^{*}$

$.341(.171)^{*}$

$644(.176)^{* *}$

$.644(.171)^{* *}$

Service Involvement $x$ Customer Inoculation (Ext. Explanation) $\rightarrow$ CS $\left(t_{2}\right)$

$-.348(.145)^{*}$

Covariates

$\mathrm{CS}\left(\mathrm{t}_{1}\right) \rightarrow \mathrm{CS}\left(\mathrm{t}_{2}\right)$

Service Involvement $\rightarrow \mathrm{CS}\left(\mathrm{t}_{2}\right)$

Anger $\rightarrow \mathrm{CS}\left(\mathrm{t}_{2}\right)$

Flight Delay $\rightarrow \mathrm{CS}\left(\mathrm{t}_{2}\right)$

Gender $\rightarrow$ CS ( $\left.\mathrm{t}_{2}\right)$

\begin{tabular}{rr}
- & $-.348(.145)^{*}$ \\
- & $-.295(.150)^{*}$ \\
$.183(.046)^{* *}$ & $.184(.046)^{* *}$ \\
- & $.305(.122)^{*}$ \\
$-.233(.064)^{* *}$ & $-.228(.063)^{* *}$ \\
$\mathrm{NS}$ & $\mathrm{NS}$ \\
$\mathrm{NS}$ & $\mathrm{NS}$ \\
. $\mathrm{NS}$ & $\mathrm{NS}$ \\
\hline
\end{tabular}

Customer Age $\rightarrow \mathrm{CS}\left(\mathrm{t}_{2}\right)$

Notes: ${ }^{* *} p \leq .01,{ }^{*} p \leq .05, \mathrm{NS}=$ not significant. $\mathrm{CS}=$ customer satisfaction with the waiting time at the baggage claim. The table shows unstandardized coefficients (SE). 
FIGURE 1

Strategies for Managing Service Failures

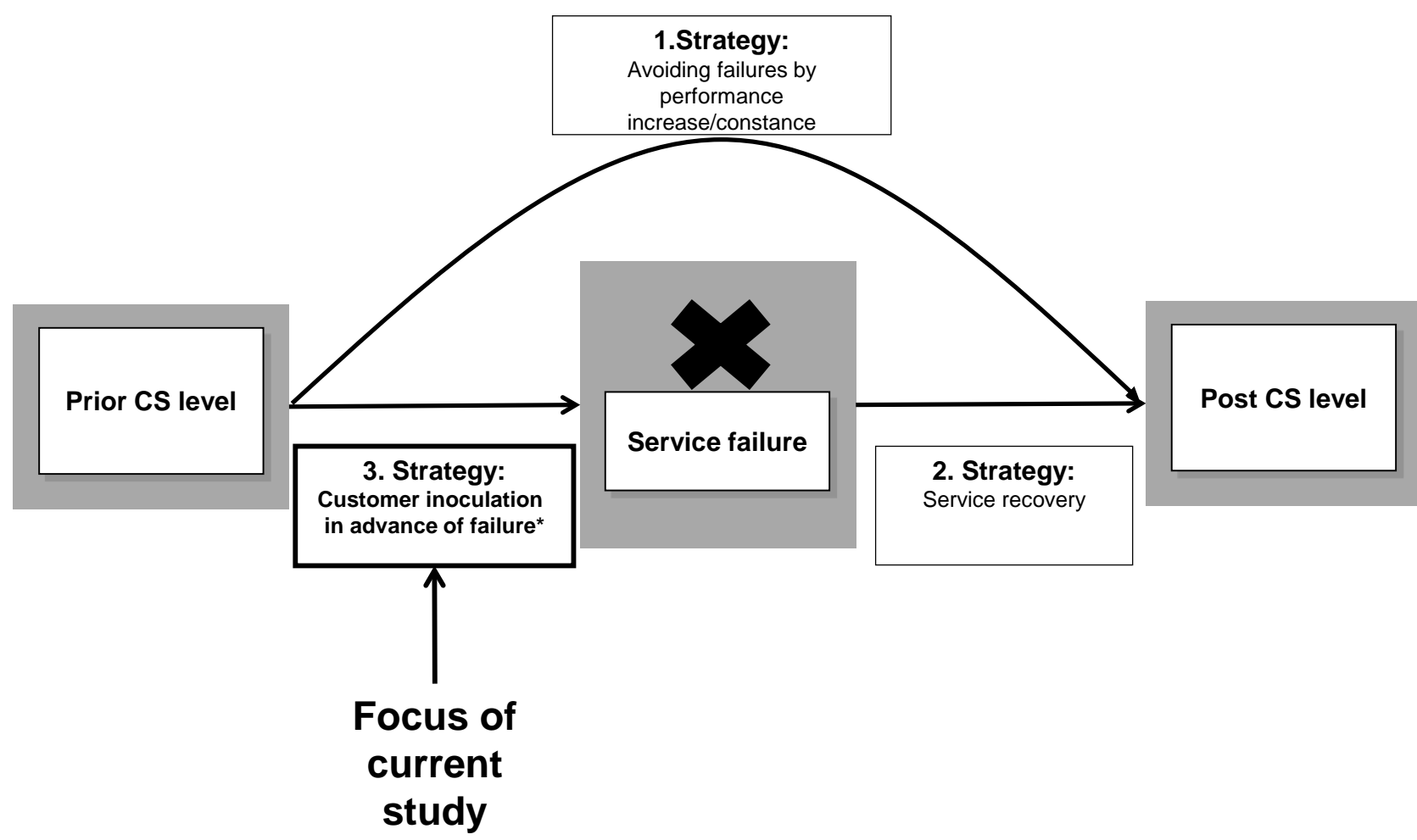

${ }^{\star}$ Note that customer inoculation is theoretically distinct from customer expectation management 
FIGURE 2

Conceptual Framework

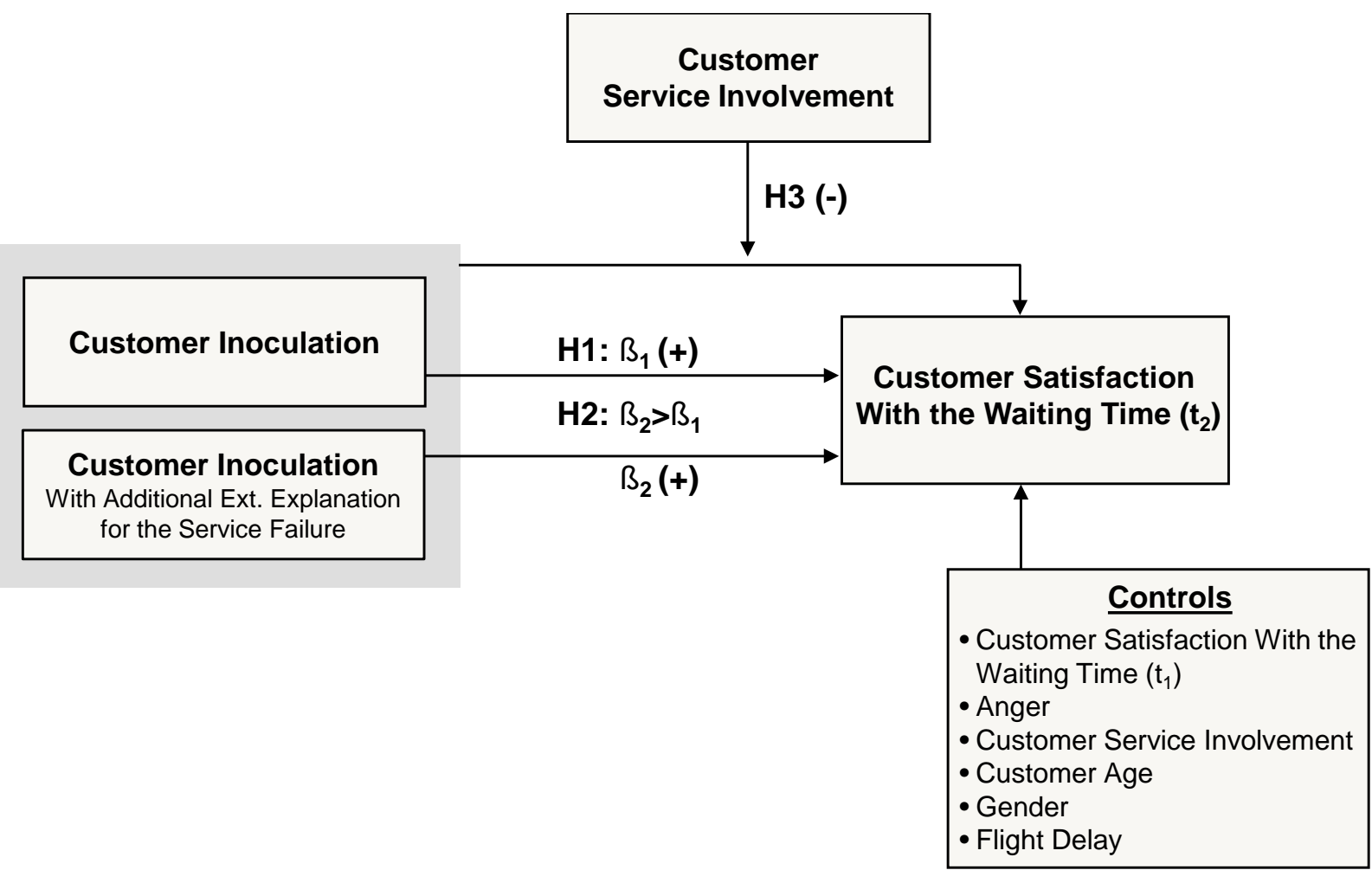


FIGURE 3

The Effect of Inoculation on Customer Satisfaction After Occurrence of a Service Failure

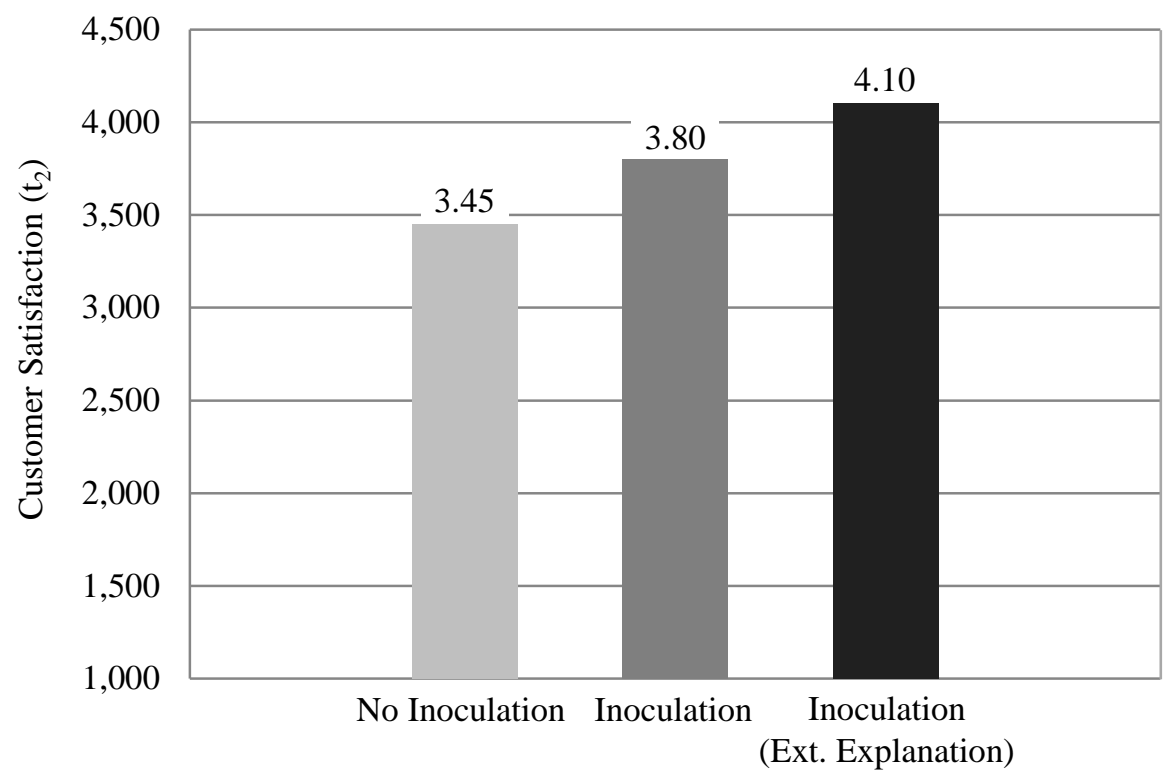

FIGURE 4

The Effect of Inoculation and Service Involvement on Customer Satisfaction After Occurrence of a Service Failure

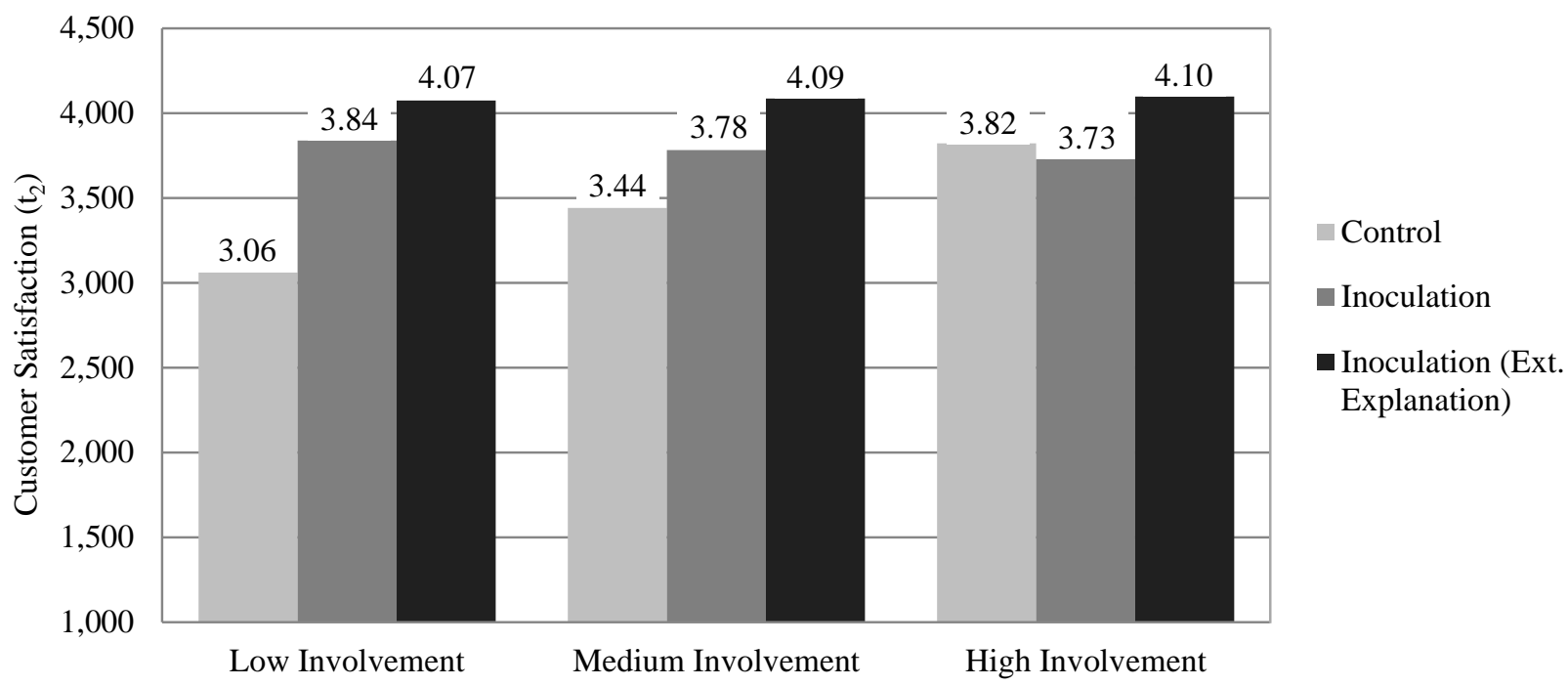

